\title{
Life Cycle Assessment of Various Filtering Media for Greywater Treatment Using Greenwall Filtration System
}

\author{
Priya B Satheesh ${ }^{1}$, Kai Siang $\mathrm{Oh}^{1,}{ }^{*}$, and Lee Hong Tee ${ }^{1}$ \\ ${ }^{1}$ School of Computer Science and Engineering, Faculty of Innovation \&Technology, Taylor's \\ University, No. 1, Jalan Taylor's, 47500 Subang Jaya, Selangor, Malaysia.
}

\begin{abstract}
The risk of global water crisis is becoming more evident due to the increase in overall global urban population and reduction of freshwater availability. Treated greywater using greenwall technology was identified as a potential method to produce water for non-potable applications. The filtering media in greenwall technology acts as a growing media for the plants and as a filtration medium. In this study, the pollutant removal efficiency and environmental impacts associated with two filtering medias (coir pith and perlite) were investigated. The coir pith was found to have higher removal efficiencies for both COD and TSS removal compared to perlite. Besides, the life cycle of each filtering media used for greywater treatment in greenwall technology were compared. Coir pith was found to have a higher environmental impact on global warming potential (1.19568 $\mathrm{kg} \mathrm{CO}_{2}$ eq.) and freshwater consumption $\left(0.00066295 \mathrm{~m}^{3}\right)$, while perlite was found to have a higher environmental impact in terms of fossil depletion $(0.045562 \mathrm{~kg}$ oil eq. $)$ and terrestrial ecotoxicity $(0.008508135 \mathrm{~kg} 1,4-\mathrm{DB}$ eq). In conclusion, this study provides a framework for in-depth data analysis of the entire life cycle of filter media and a decision-making tool for the selection of suitable filtering media for greenwall filtration system.
\end{abstract}

\section{Introduction}

Currently there has been an exponential rapid growth in the overall urban population in the world. This issue tied with the reduction of natural freshwater availability can lead to a global water scarcity crisis. Based on the United Nations Department of Economic and Social Affairs (UNDESA), it was noted by the year 2025, two-thirds of the world will face shortages in water supply causing a global crisis [1]. One of the alternative water sources to replace freshwater in non-potable application is greywater. Greywater is household wastewater generated from bathroom sinks, showers, bathtubs, kitchen appliances and washing machine [2]. In general, greywater consists dirt, fragments of food/grease, household cleaning products and etc [2]. Treated greywater has the prospects to be an alternative source of water for the operation of toilet flushing, garden irrigation and for urinals, ultimately reducing the

* Corresponding author: KaiSiang.Oh@taylors.edu.my 
consumption of freshwater supply [2]. By using greywater, which has been treated in accordance to the governmental standards to replace freshwater, domestic water usage can be reduced by up to $46 \%$ [3]. Despite the advantages of greywater recycling, there is still challenges in the research community on the application of greywater due to the possible risks caused by the pollutants present in the greywater such as COD, BOD, TSS, microorganisms and etc.

Pollutants are sources that can cause hazard to the environmental balance and health of organisms. The treatment of these pollutants are vital to maintain a balanced ecosystem. The quality of the greywater is based on the pollutants found in the body of water such as COD (96-587 mg/L), BOD (39-155 mg/L) and TSS (37-283 mg/L) [4]. These components are introduced to greywater from the usage of pharmaceutical products, personal care products, household products, cleaning products, food additives and pesticides [5]. Some of the current forms of pollutant removal from greywater is done via biologically, physically, chemically and through natural treatments [3]. One distinctive method, considered as an environmentally friendly alternative in the removal of pollutants in greywater is using a greenwall technology via filtering medias to treat the greywater which comprises of physio-chemical and biological treatments.

Greenwalls are known as living walls or vegetated walls comprised of vegetation based on a growing media arranged vertically [6]. These walls have major potentials in its capabilities for the management of water recycling. From previous research, it was shown that the green wall can act as an ecological filtering system (sand and gravel) to remove COD, BOD and TSS in greywater up to $90 \%$ [6]. Based on the characteristics of the sand and gravel mixture that has high hydraulic retention rate and good filtering capabilities, it has high potential for the removal of pollutants especially COD. However, the problem faced is that sand and gravel are unsuitable for greenwall as the medias are not light weight [7]. To be implemented in a greenwall system, the filtering medias need to be lightweight in nature as to reduce the load on the greenwall supporting structure [7]. The filter media in the green wall plays an important role in the removal of the pollutants in the grey water by acting as a sieve to capture the unwanted substances to generate a clean usable water supply. The removal mechanism that is used for the decontamination process of greywater using the filter medias is through physio-chemical removal and biological removal. For physio-chemical removal, it involves physical removal (straining) and chemical removal (adsorption) while biological removal involves the biodegradation of pollutants through microbial processes [6].

The greenwall technology is a highly potential and sustainable method to combat the reduction of freshwater availability currently occurring. In the road to make greenwall technology more sustainable and efficient it is important to assess the viability and environmental impacts caused by the filter medias. In this research, the tool to assess the potential environmental impact of different filtering medias throughout its life cycle is based on the life cycle assessment (LCA). LCA is the complete analysis of the entire life cycle of the filter media based on input and output data obtained and generates the environment impacts it has caused. There are research present regarding the LCA of the greenwall technology from the manufacturing to disposal, however there is a lack of emphasis on the impact of the growing media on the environment [8-9]. By obtaining a better comprehension on the environmental impacts of each filter medias, it can lead to further optimization of this technology for efficient and sustainable water management. Currently there is a research gap due to the lack of study done to assess the environmental impacts of different types of filter media in a greenwall system. This study focuses on the evaluation of COD and TSS pollutant removal efficiency of different filter medias in greywater treatment in a greenwall system. This is done to address the lack of comparison in different filter medias capabilities in removing pollutants from greywater via greenwall and to ultimately find the most efficient filter media in pollutant removal that can be used for greenwall designing purposes. At the 
same time, this study also serves to report the environmental impacts caused throughout the life cycle of different filter medias for greenwall technology using LCA. The LCA will be able identify the degree of environmental impact each filter media contributes that can be a useful decision-making tool when designing greenwall systems for greywater treatments.

\section{Methodology}

\subsection{Evaluation of filter media capabilities for greywater treatment in greenwall}

The 2 types of filter media, coir pith and perlite are chosen to be used as the filtering media and growing media in the greenwall system due to its wide usage in horticultural purposes and physical and chemical characteristics suitable as a filtration medium. Coir pith is popular as growing media in horticulture sectors due to its ability to maintain moisture and reconditioning soil which enhances the nutrient carrying capacity of plants [10]. Perlite is popular in the same sector as due to its ability to aerate and drain the soil in the meantime maintaining the nutrients in the soil [10]. Based on the use in horticulture and its individual characteristics, it was chosen due to its potential as a filtering media. A literature survey was done by collecting results from past journals, articles, and peer reviewed papers regarding the filtration capabilities of the materials for greywater. The research materials were obtained by using databases such as JSTOR, ScienceDirect, Elsevier, SpringerLink and etc. the research papers are filtered by using keywords such as greenwall system, greywater, pollutants, filter medias and removal efficiency. By using the databases, relevant research materials that contain information regarding the 2 materials as a filtration media were collected. The capabilities of the pollutant removal efficiency of the filters are analyzed based mainly on COD and TSS removal efficiency as most studies conducted analyzed the removal efficiencies based on these 2 components. A comparative analysis was conducted on the efficiency in removal ability of COD and TSS in greywater using each of the filter media by analyzing the data collected and the removal mechanisms of each filter media. The best fit line that best describe the removal of pollutant using both Langmuir isotherm and Freundlich isotherm was obtained based on a few case studies related to the adsorption models of the relating filter medias. The best fit line equation of Langmuir isotherm and Freundlich isotherm shown in Equation (1) and Equation (2) respectively will be used to check if the concentration of pollutant adsorbed value, $\mathrm{q}_{\mathrm{e}}$ using the best fit line equation tallies with the actual concentration of pollutant adsorbed and if the best fit line equation can be adopted to predict the $\mathrm{q}_{\mathrm{e}}$ for each filter media [11].

Langmuir model best fit line equation:

$$
1 / \mathrm{q}_{\mathrm{e}}=\mathrm{C}_{1}\left(1 / \mathrm{S}_{\mathrm{e}}\right)+\mathrm{C}_{2}
$$

Freundlich model best fit line equation:

$$
\ln \mathrm{q}_{\mathrm{e}}=\mathrm{C}_{3} \ln \mathrm{S}_{\mathrm{e}}+\mathrm{C}_{4}
$$

Where,

$\mathrm{q}_{\mathrm{e}}=$ concentration of pollutant adsorbed

$\mathrm{S}_{\mathrm{e}}=$ concentration of pollutants at equilibrium

$\mathrm{C}_{\mathrm{i}}=$ constants 


\subsection{Life cycle assessment of different filter medias}

\subsubsection{Goal and scope}

For the LCA methodology, the standard that will be based on is the ISO 14040:2006 and ISO 14044: 2006 standards [12]. These standards of assessment involve the framework of goal and scope definition, inventory analysis, impact assessment, interpretation phase and the reporting and critical review of the LCA as set by the International Organization for Standardization (ISO) [12]. The GaBi software Version 9.2.1 will be utilized in this research for the LCA. The first step in LCA is to identify the goal and scope of the research. For this research, the purpose of the LCA is set to compare the environmental impacts of each filter medias during its entire life cycle. By understanding the major environmental burdens of each filter medias, the proper filter media can be chosen to be implemented in the greenwall technology based on the least amount of environmental burden and with optimum pollutant removal rate.

For this LCA, the system boundary is set for cradle to grave consisting of 5 main stages; production of filter medias, packaging, transportation, usage of medias as greenwall technology filters and the recycling/waste management at the end of life. For each filter media, the specific details of each of the stages are different, however they share the same general flow as mentioned previously.

As for the functional unit, FU it differs for each filter media as it is based on the capabilities to remove $80 \%$ of COD as mentioned previously. The removal efficiency of COD is benchmarked at $80 \%$ to meet the regulative standards for water discharge. The basis of the functional unit is set in terms of mass as most of the information required for data inventory are in mass basis. The FU for each filter media is found by comparing different literature reviews that have conducted greywater treatments for each individual filter. For each corresponding COD removal and volume of filter used in different literatures, the values are interpolated to align with $80 \%$ COD removal efficiency. This method of FU identification allows for fair assessment of the environmental impacts of each filter media to remove the same amount of COD from greywater. For this research, $0.211 \mathrm{~kg}$ of coir pit and $0.290 \mathrm{~kg}$ of perlite will be set as the functional unit based on its ability to remove $80 \%$ of COD from greywater.

\subsubsection{Life cycle inventory analysis}

The life cycle inventory analysis is conducted to collect the compilation of information regarding the mass and energy transfer within the system boundary currently known for each filter media. Data related to production of filter media, packaging, transportation, usage of filter media in greenwall and the waste management was obtained through relevant and credible literature sources in the form of journals, publications, previously conducted LCA and databases in relating to the topic [13]. Besides finding data based on literature reviews, inventory databases or softwares such as Ecoinvent and $\mathrm{GaBi}$ will be used. These databases/softwares provide accessibility to updated data on energy, cost and environmental impact based on a range of materials used. The data collected relating to the amount of materials used in each of these stages will be based as per FU of each respective filter media.

The coir pith production begins with the extraction of $1.846 \mathrm{~kg}$ of coconut to produce $0.211 \mathrm{~kg}$ of coir pith [14]. The coconut is de-nutted and placed in a brackish water body for the process of retting. For the retting of $0.211 \mathrm{~kg}$ of coir pith, $5.53 \mathrm{~kg}$ of brackish water per FU is needed to separate the coir pith from the rest of the coconut [15]. The retting process causes the emission of 2 main biogases; methane at $0.0328 \mathrm{~kg} \mathrm{CH}_{4} / \mathrm{FU}$ and carbon dioxide at $0.0457 \mathrm{~kg} \mathrm{CO}_{2} / \mathrm{FU}$ due to the anaerobic fermentation process caused by the active microbes 
in the water [16]. Once the retting process is completed, the softened fibers are collected and put through a flat beater arm operated inside a steel drum that has an electricity consumption of $0.0114 \mathrm{kWh}$ to process $0.211 \mathrm{~kg}$ coir pith to undergo defibering [17]. The collected coir pith is then washed with $0.633 \mathrm{~kg}$ freshwater/FU to remove any remaining dusts or contaminants and put out to Sun dry [18]. The coir pith is then packaged using a coir pith packaging machine operating at $0.00393 \mathrm{kWh}$ using $1.61 \mathrm{~kg}$ of packaging bag/ FU for 0.211 kg coir pith [19]. The electricity supplied for both the manufacturing process and packaging is based on Malaysian Electricity Grid Mix in GaBi Software. The packaged coir pith is then transported using GLO: Truck; Euro 2 in GaBi Software with diesel consumption of 0.00234 $\mathrm{kg} / \mathrm{FU}$. The coir pith is transported to the location where it will be implemented into the greenwall system as a filtering media. LCA will not be conducted in this stage as it is assumed that the environmental impact for this stage will be constant for all the filtering medias. Once the coir pith has lost its capabilities in pollutant removal, it is removed and used undergoes composting as the end-of-life solution. For the composting of $0.211 \mathrm{~kg}$ coir pith, $0.0011 \mathrm{~kg}$ urea and $0.0003165 \mathrm{~kg}$ of Pleurotus spawn is used to produce $0.211 \mathrm{~kg}$ of biomass [20]. The composting process causes the emission of $0.000386 \mathrm{~kg} \mathrm{CH}_{4} / \mathrm{FU}, 0.0000158 \mathrm{~kg} \mathrm{~N}_{2} \mathrm{O} / \mathrm{FU}$ and $0.0000856 \mathrm{NH}_{3} / \mathrm{FU}$ [21]. At this stage, the coir pith has reached its end-of-life.

The production of perlite begins with the mining of $0.290 \mathrm{~kg}$ perlite ore to produce 0.290 $\mathrm{kg}$ perlite which produces $0.339 \mathrm{~kg}$ waste rock/FU as waste [22]. The mined perlite is then crushed, dried, and grinded [23]. The perlite is then put through a furnace for the expansion of the perlite at temperatures between $\left(760^{\circ} \mathrm{C}\right.$ to $\left.980{ }^{\circ} \mathrm{C}\right)$. The furnace is fueled by $1.71 \mathrm{MJ}$ natural gas/FU in order to increase the temperature to such high temperatures [23]. The perlite is then passed through a cyclone to remove any contaminants. During the entire production process of the perlite, $0.00861 \mathrm{kWh}$ of electricity was consumed, $0.0000815 \mathrm{~kg}$ particulate matter/FU and $0.0000125 \mathrm{~kg} \mathrm{CO}_{2} / \mathrm{FU}$ was emitted to produce $0.290 \mathrm{~kg}$ perlite [22-24]. The collected perlite is then packaged into $2.02 \mathrm{~kg}$ package bag/FU using a perlite packaging machine that consumes $0.000435 \mathrm{kWh}$ of electricity [25]. The electricity supplied for both the manufacturing process and packaging is based on Malaysian Electricity Grid Mix in GaBi Software. The packaged perlite is then transported using GLO: Truck; Euro 2 in GaBi Software with diesel consumption of $0.00068 \mathrm{~kg} / \mathrm{FU}$. The perlite is transported to the location where it will be implemented into the greenwall system as a filtering media. LCA will not be conducted in this stage as it is assumed that the environmental impact for this stage will be constant for all the filtering medias. Once the perlite losses its ability as a pollutant remover, it is transported to a landfill to be disposed that has a fixed process in GaBi under Glass/Inert Waste on Landfill. At this stage, the perlite has reached its end-of-life.

\subsubsection{Impact assessment}

The impact assessment is conducted based on the ISO 14044 standards requiring for elements such as impact categories, category indicators and characterization models [12]. $\mathrm{ReCiPe}$ model is in GaBi Software is used to analyze the potential of the environmental based on 18 midpoint impact categories by a category indicator [13]. For the calculation of impact, first the quantity of materials, energy and emissions generated in the system are identified and grouped based on its contribution to the appropriate impact categories. The quantity is multiplied by the characterization factors to reflect the environmental impact of the substance [26]. The result calculates the impact of the substances in terms of the unit for each impact categories. The impact is calculated using the GaBi Software and using manual calculation (as shown in Equation (3)) for processes that are not in the GaBi Software. Based on the magnitude of the impact category for each filter media, the results of was compared for each filter media. 
Input $\times$ Emissions $\times$ Characterization Factor $=$ Environmental Impact

\section{Results and Discussion}

\subsection{Evaluation of filter media capabilities for greywater treatment in greenwall}

\subsubsection{Removal efficiency of filter medias}

Based on the literature survey conducted, Table 1 shows a summary of removal efficiency of each filter media. The TSS removal from the experiment showed that perlite, a fast media, was able to remove $73 \%$ of TSS, while the coir pith, a slow media, was able to remove 92 $\%$ of TSS from the greywater [27]. This was inferred to be due to the lesser spaces between the pores in the filter media categorized as slow. When the pore spaces are smaller, this causes the higher straining performance of the filter media thus creating a form of restriction for the solids to pass through the filters. This results in a higher water retention time of the filter media for the greywater with pollutants to pass through the pores. By having a higher hydraulic retention time, the possibility of the pollutants being adsorbed onto the filters also increase [28]. The small spaces in between the pores create an entrapment of the TSS that has larger size than the spaces between pores, preventing it from flowing down to the outlet of the greenwall system as shown in Figure 1.

Table 1. COD and TSS removal from greywater before and after treatment. [27]

\begin{tabular}{|c|c|c|c|c|c|}
\hline \multirow[t]{2}{*}{ Parameters } & \multirow{2}{*}{$\begin{array}{c}\text { Greywater } \\
\text { before } \\
\text { treatment }\end{array}$} & \multicolumn{2}{|c|}{ Greywater after treatment } & \multicolumn{2}{|c|}{ Removal Efficiency (\%) } \\
\hline & & Coir Pith & Perlite & Coir Pith & Perlite \\
\hline $\operatorname{COD}\left(\mathrm{mg} / \mathrm{L}^{-1}\right)$ & 170 & 42.5 & 125.8 & 75 & 26 \\
\hline $\mathrm{TSS}\left(\mathrm{mg} / \mathrm{L}^{-1}\right)$ & 76 & 6.02 & 20.52 & 92 & 73 \\
\hline
\end{tabular}

In terms of the perlite categorized as a fast media, the spaces between the pores are larger leaving the TSS able to pass through the looser pore arrangement [27]. This allows higher concentrations of TSS to pass the system, without being filtered out. However, when time passes, the TSS will eventually begin to fill the void between the pores, thus it will have higher potential for TSS removal [27]. This is because when the TSS fills up the spaces between pores, the pore spaces will decrease causing higher concentrations of TSS to be entrapped on the layer of the pores, thus straining more TSS away from the greywater effluent [28].

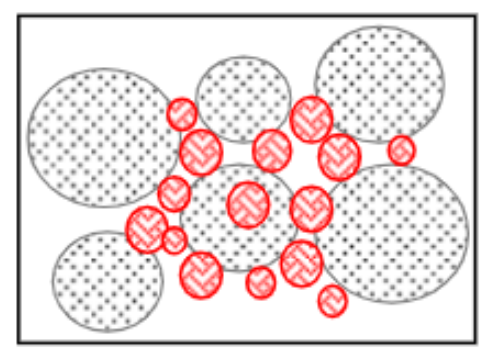

Fig. 1. Entrapment of TSS in between pore spaces [28]

The perlite was able to show a COD removal rate of $26 \%$, while the coir pith was able to remove $75 \%$ of the COD [27]. The structure of coir piths enables it to have a higher retention time compared perlite [27]. This enables the greywater present with pollutants to spend 
longer time within the structures of coir pith compared to the perlite. By having a higher retention time, the pollutants will be able to undergo longer physio-chemical (straining and adsorption) and biological process in the pores of the filters [27]. Similar to the TSS, when the organic pollutants are trapped in the filter, it spends longer time within the pores thus there will be a higher rate of bacteria within the filters to cause the organic pollutants degradation. The more organic pollutants are removed, the lower the COD value of the effluent [29]. It can be assumed that the trend is similar for BOD removal of each filter media whereby the coir pith will show a higher removal rate compared to the perlite.

\subsubsection{Adsorption isotherms}

To evaluate the adsorption capabilities of the filter medias, journals that have conducted study based on adsorption isotherms of the filter medias or materials that have similar chemical properties as the filter media are assessed. Based on a research that evaluated the ability of coconut waste as an adsorbent by using isotherm models, the results produced of $\mathrm{R}^{2}$ for Langmuir Isotherm model and Freundlich Isotherm model was found to be 0.94 and 0.99 respectively [30]. Based on a research that evaluated the ability of a perlite mixture as an adsorbent by using isotherm models, the results produced of $\mathrm{R}^{2}$ for Langmuir Isotherm model and Freundlich Isotherm model was found to be 0.9984 for both models [31]. Based on the analysis of the $\mathrm{R}^{2}$ data of each isotherm in Table 2 it can be observed that it shows that the coir pith and perlite are favorable to both Langmuir isotherm and Freundlich isotherm due to the high $\mathrm{R}^{2}$ values.

Table 2. Langmuir Isotherm and Freundlich Isotherm correlation isotherm for coir pith and perlite

\begin{tabular}{|c|c|c|c|}
\hline \multirow{2}{*}{ Parameters } & \multicolumn{2}{|c|}{$\mathbf{r}^{\mathbf{2}}$} & \multirow{2}{*}{ References } \\
\cline { 2 - 3 } & $\begin{array}{c}\text { Langmuir } \\
\text { Isotherm }\end{array}$ & $\begin{array}{c}\text { Freundlich } \\
\text { Isotherm }\end{array}$ & \\
\hline Coir pith & 0.94 & 0.99 & {$[30]$} \\
\hline Perlite & 0.9984 & 0.9984 & {$[31]$} \\
\hline
\end{tabular}

To further evaluate adsorption of pollutants on the filter medias, the best fit line from the isotherms in Table 3 from journals that have studied the adsorption model of the filter media is used to check if the data from Table $1 \mathrm{can}$ fit in best fit line equation to produce the same concentration of pollutants adsorbed, $\mathrm{q}_{\mathrm{e}}$ as the $\mathrm{q}_{\mathrm{e}}$ derived from the data in Table 1. For the coir pith, the $\mathrm{q}_{\mathrm{e}}$ calculated based on the best-fit line equation from the Langmuir model and Freundlich model derived from the journal that focuses on the adsorption model on COD removal using coconut waste was found to be 1.005 and 0.203 respectively as shown in Table 3. The $\mathrm{q}_{\mathrm{e}}$ from Langmuir equation was found to be very close to the $\mathrm{q}_{\mathrm{e}}$ value of 0.971 shown in Table 3 derived from data in Table 1 which may be because the coconut waste has similar chemical molecular structure as coir pith, thus the adsorption capabilities are similar. The Langmuir best fit line equation can be used to approximately predict the pollutant adsorbed capability of coir pith due to the low discrepancy. The $\mathrm{q}_{\mathrm{e}}$ from Freundlich equation was found to be have a large discrepancy to the $\mathrm{q}_{\mathrm{e}}$ value of 0.971 as shown in Table 3 derived from data in Table 1 which may be due to the reason that the Freundlich model takes into account the interactions between adsorbates [11]. This can cause the discrepancy as the interactions between the adsorbates from the journal in Table 1 may not interact the same as the study of the adsorption model research. The Freundlich best fit line equation cannot be used to predict the pollutant adsorbed capability of coir pith due to the high discrepancy. Additional research is required to further justify the determent of the $\mathrm{q}_{\mathrm{e}}$ value calculated from the Freundlich model equation from the actual $\mathrm{q}_{\mathrm{e}}$ value. 
Table 3. Langmuir Isotherm and Freundlich Isotherm best-fit line equation and $\mathrm{q}_{\mathrm{e}}$

\begin{tabular}{|c|c|c|c|c|c|c|}
\hline \multirow[b]{2}{*}{$\begin{array}{l}\text { Type } \\
\text { of } \\
\text { Filter }\end{array}$} & \multirow[b]{2}{*}{$\begin{array}{c}\text { qe } \\
\text { based } \\
\text { on } \\
\text { Table 1 } \\
\text { data } \\
(\mathrm{mg} / \mathrm{g}) \\
\end{array}$} & \multicolumn{2}{|c|}{ Langmuir Model } & \multicolumn{2}{|l|}{ Freundlich Model } & \multirow[b]{2}{*}{ References } \\
\hline & & Best-fit line equation & $\begin{array}{c}\mathrm{qe} \\
\text { based } \\
\text { on } \\
\text { model } \\
(\mathrm{mg} / \mathrm{g}) \\
\end{array}$ & Best-fit line equation & 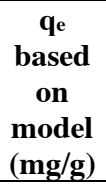 & \\
\hline $\begin{array}{l}\text { Coir } \\
\text { Pith }\end{array}$ & 0.971 & $\frac{1}{q_{e}}=47.83 \frac{1}{S_{e}}-0.13$ & 1.005 & $\ln q_{e}=2.54 \ln S_{e}-11.12$ & 0.203 & {$[30]$} \\
\hline Perlite & 0.812 & $\frac{1}{q_{e}}=0.027 \frac{1}{S_{e}}+7.4$ & 0.135 & $\ln q_{e}=0.704 \ln S_{e}-6.57$ & 0.043 & {$[31]$} \\
\hline
\end{tabular}

For the perlite, the $\mathrm{q}_{\mathrm{e}}$ calculated based on the best-fit line equation from the Langmuir model and Freundlich model derived from the journal that focuses on the adsorption model on COD removal using perlite mixture (perlite and activated sludge) was found to be 0.135 and 0.043 respectively as shown in Table 3 . Both the models were found to be have a large discrepancy to the $\mathrm{q}_{\mathrm{e}}$ value of 0.812 as shown in Table 3 derived from data in Table 1 . The deviation in $\mathrm{q}_{\mathrm{e}}$ value maybe due to the presence of activated sludge in the mixture that acts as a biological treatment by breaking down the organic matter in the liquid which then reduces the COD concentration in the water [31]. This reduces the role of the perlite as an adsorbent to adsorb the remaining COD concentration as the biological treatment due to activated sludge is more dominant which justifies the deviation of the $\mathrm{q}_{\mathrm{e}}$ from the adsorption isotherm model to the actual $\mathrm{q}_{\mathrm{e}}$ value [31]. Both the Langmuir and Freundlich best fit line equation cannot be used to approximately predict the pollutant adsorbed capability of perlite due to the high discrepancy. Additional research is required to further confirm the mechanism that caused the variation in $\mathrm{q}_{\mathrm{e}}$ values.

In terms of adsorption mechanism, the process includes 2 components that is adsorbate and adsorbent [32]. The adsorbate in this case is the organic materials in greywater, while the absorbent is the filter medias. The process begins as the organic materials passes through the macro-pore system of the filter media known as the macro transport, then the subsequent transportation of the pollutants through the meso-pore and micro-pore structures in the filter media [33]. Finally, the organic material will attach onto the meso-pores and micro-pores of the filter media [33]. However, each filter media has its own degree of affinity thus creating the difference in adsorption rate [33]. According to Prodanovic et al. [32], it was hypothesized that the reasoning for coir piths ability for high organic material adsorption rate is due to the carbon present in the chemical structure.

Besides adsorption, researchers also have analyzed biological removal mechanism that also occurs through the filtering media that involves the action of microbial processes [32]. The process begins as the greywater passes through the filters. Besides acting as a strainer for removing solids, the filter also creates a surface for bacteria and microorganisms to stick onto. This creates an environment for vegetation to begin due to the continuous source of water, moisture and nutrients supplied by the greywater [6]. The plant attached to the greenwall, that has the roots embedded and intertwined with the filter medias creates an aerobic environment due to the release of oxygen towards the rooting area [6]. This creates an optimum condition for aerobic bacteria to absorb the organic matters that passes through the filter surface area and cause it to undergo biodegradation whereby the bacteria breakdowns the organic matters [6]. The biodegraded nutrients and organic matters are then absorbed by the plants as a source of mineral and nutrients, thus creating a fertilization medium for the plants [6]. 


\subsection{Life cycle assessment}

The results are based on the cradle to grave system boundary of the filter medias life cycle as shown in Figure 2. The impact caused by the greenwall application for both the filter medias is not shown in the graphs as the impact of this stage is similar to both filtering media thus it will be excluded. Figure 2 shows the cradle to grave life cycle of coir pith and perlite that will be considered for the life cycle assessment.

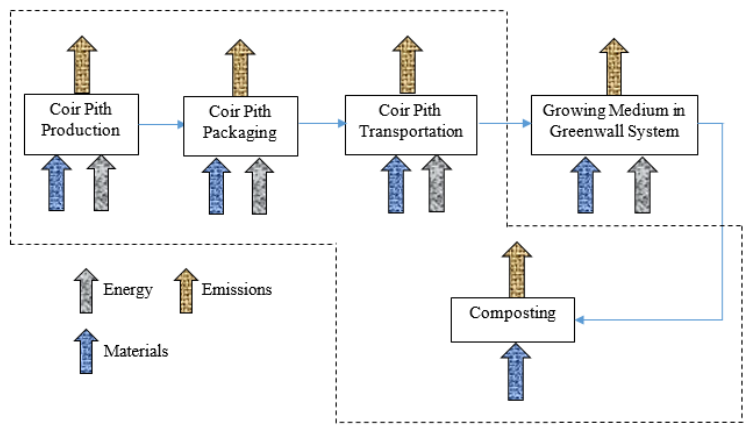

(a)

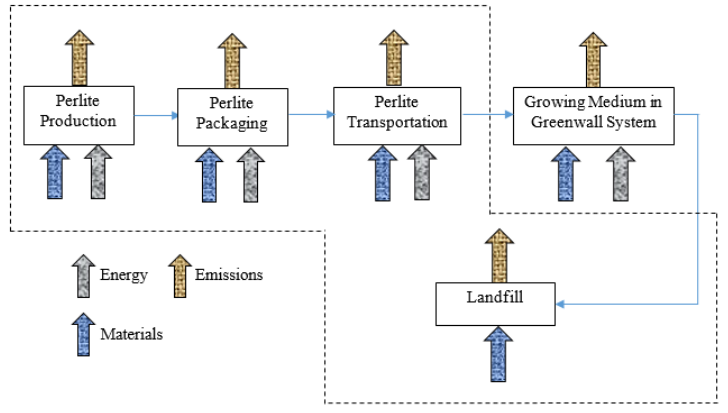

(b)

Fig. 2. (a) Coir pith cradle to grave life cycle. (b) Perlite cradle to grave life cycle.

\subsubsection{Environmental impacts of coir pith}

Figure 3 shows the contribution of environmental impact each stage in the life cycle of the coir pith from cradle that includes the coir pith manufacturing, packaging, transportation, greenwall application and end-of-life through composting. In this section, the impact categories that has significant impacts will be discussed. As shown in Figure 3, the coir pith manufacturing stage dominates most of the impact categories including terrestrial acidification, stratospheric ozone depletion, marine eutrophication, land use and fine particulate matter. At the mentioned categories, the end-of-life by composting dominates the categories. The manufacturing stage is the highest in the global warming potential at $98.1 \%$ due to the release of methane and carbon dioxide during the retting process of the coir pith caused by the anaerobic digestion process [16]. The impact category global warming potential is related to the emissions of greenhouse gases such as carbon dioxide, methane, nitrous oxide and Chlorofluorocarbon (CFC) that causes the temperature of the Earth's climate [34]. The composting stage also produces methane and nitrous oxide gases; however, the release quantity is relatively smaller than the greenhouse gases (GHG) produced during the retting stages of coir pith [21]. Besides that, the water consumption impact category has a large presence in the manufacturing stage at $98.9 \%$. This is because amongst the other stages, the manufacturing stage consumes large amounts of water in terms of the brackish water needed for retting and the freshwater needed for coir pith cleaning $[15,18]$. The other stages do not consume as much water as it is mostly only derived from the electricity flow. For fossil depletion, the manufacturing, packaging and transportation has high contributions for this category at $64 \%, 21 \%$ and $14.91 \%$ respectively. This is due to the usage of natural gas and crude oil to generate electricity (manufacturing and packaging) and fuel (diesel for transportation). The electricity generation especially contributes highly to the fossil depletion mainly from manufacturing as high electricity demand is needed to operate the beater. The land use impact category shows dominance in the end-of-life at $99.97 \%$ where composting of the coir pith takes place. During composting, a certain portion of a land is needed to be transformed through digging and additives such as urea and Pleurotus spawn is added to create an environment for composting [20]. The entire composting process causes disruption 
on the original structure of the land and soil. For terrestrial acidification, the highest contributor is the end-of-life stage through composting at $79.82 \%$. The composting stage releases and leaches ammonia to the soil, which is a contributing factor to terrestrial acidification [34]. The increase of $\mathrm{H}+$ concentration causes the $\mathrm{pH}$ of the soil to increase thus altering the ecosystem in the soil [34]. For terrestrial ecotoxicity, the main contributor is from the manufacturing at $70.11 \%$ due to the high electricity consumption. For electricity flow, it contains emissions of toxic substances to the environment impacting the surrounding habitat.

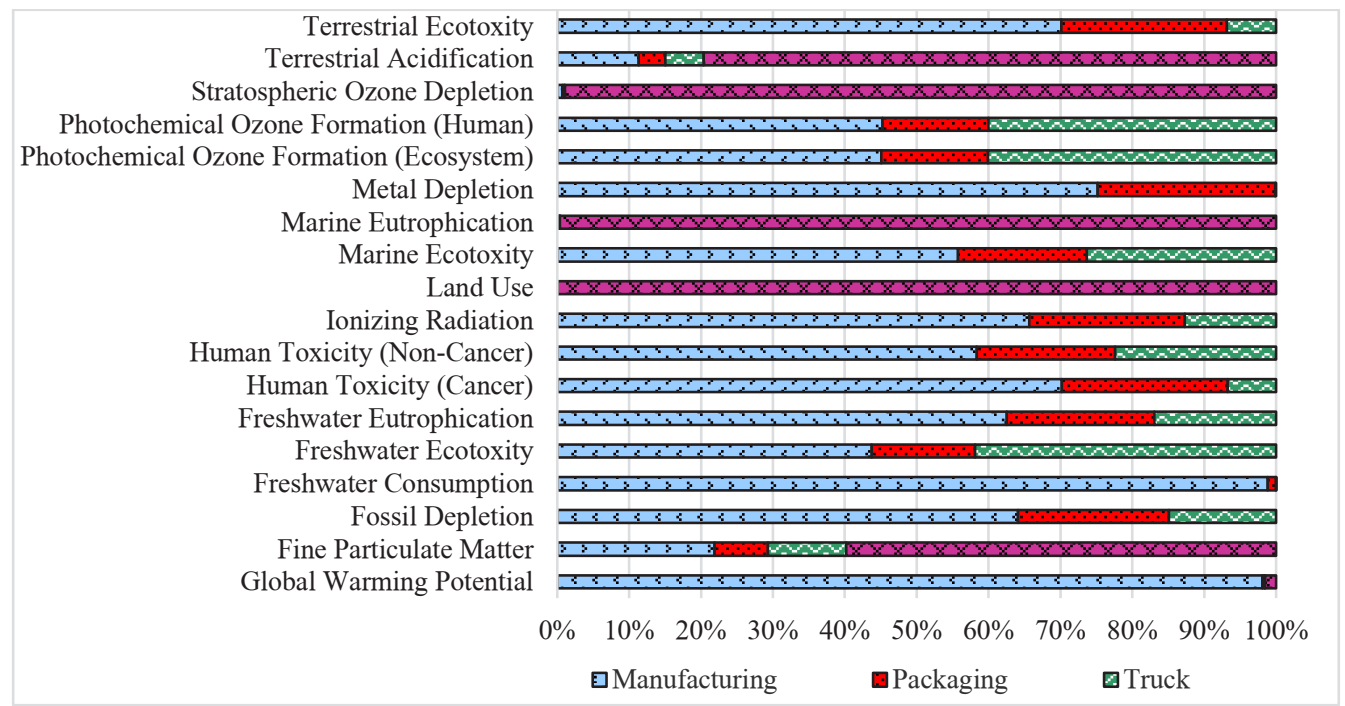

Fig. 3. Impact assessment for coir pith cradle-to-grave system boundary

\subsubsection{Environmental impacts of perlite}

Figure 4 shows the list of impact categories and the contribution of each stages in the cradle to grave system boundary of the perlite. The system boundary for perlite consists of manufacturing stage, packaging phase, transportation phase (truck), greenwall application and end-of-life phase where the perlite is sent to a landfill. In this section, impact categories that have significant impact to the environment will be discussed. The first impact category found to have a significant impact is the global warming potential. The perlite system boundary has significant presence in this category, contributed mainly by the manufacturing phase of the perlite at $50.33 \%$. During the manufacturing phase, natural gas (mainly of methane) is used to fuel the furnace operating at very high temperatures $\left(760{ }^{\circ} \mathrm{C}\right.$ to $\left.980{ }^{\circ} \mathrm{C}\right)$ required for the expansion process of the perlite [23]. The burning of the natural gas contributes to the release GHG such as carbon dioxide, methane and nitrous oxide [34]. These gases are responsible in increasing the temperature of the surrounding environments. The landfill also contributes partly to this category at $30.07 \%$, as disposing perlite in a landfill can cause emissions of GHG to the environment [34]. The next impact category that has a large environmental impact is the fossil depletion. As previously mentioned, natural gas is used as a fuel source for the furnace during manufacturing. At this point, the consumption of high volumes of natural gas can eventually drastically decrease the supply if used up too much as it is a non-renewable resource. Compared to the manufacturing stage (95.02\%), the packaging and transportation (truck) shows minor contribution to fossil depletion at $0.22 \%$ and $1.77 \%$. This is due to the electricity consumption and diesel usage needed for both of the phases, which both consume amounts of non-renewable sources that contribute to fossil 
depletion. Through the burning of natural gas through the furnace, gases besides the ones mentioned previously is also released such as carbon monoxide, nitrogen oxide and sulfur dioxide [34]. These gases released during natural gas burning contribute to the human toxicity (non-cancerous). Human toxicity impact category considers the emissions of chemicals in the environment (land, water, soil) [34]. The disposal of perlite in the landfill is also shown to contribute to the human toxicity category. When perlite interacts with other components in the landfill, the interaction also releases emissions that contribute to the human toxicity category. For the end-of-life of the perlite, it is sent to a landfill to be disposed. As shown in Figure 4, the land use impact category is mainly due the end-of-life stage of the perlite at $71.58 \%$. By disposing perlite into a landfill, it consumes more land space. The more land space consumed to be used as a landfill for perlite, the more the habitat changes making it inhabitable for living organism thus changes the entire ecosystem of the land.

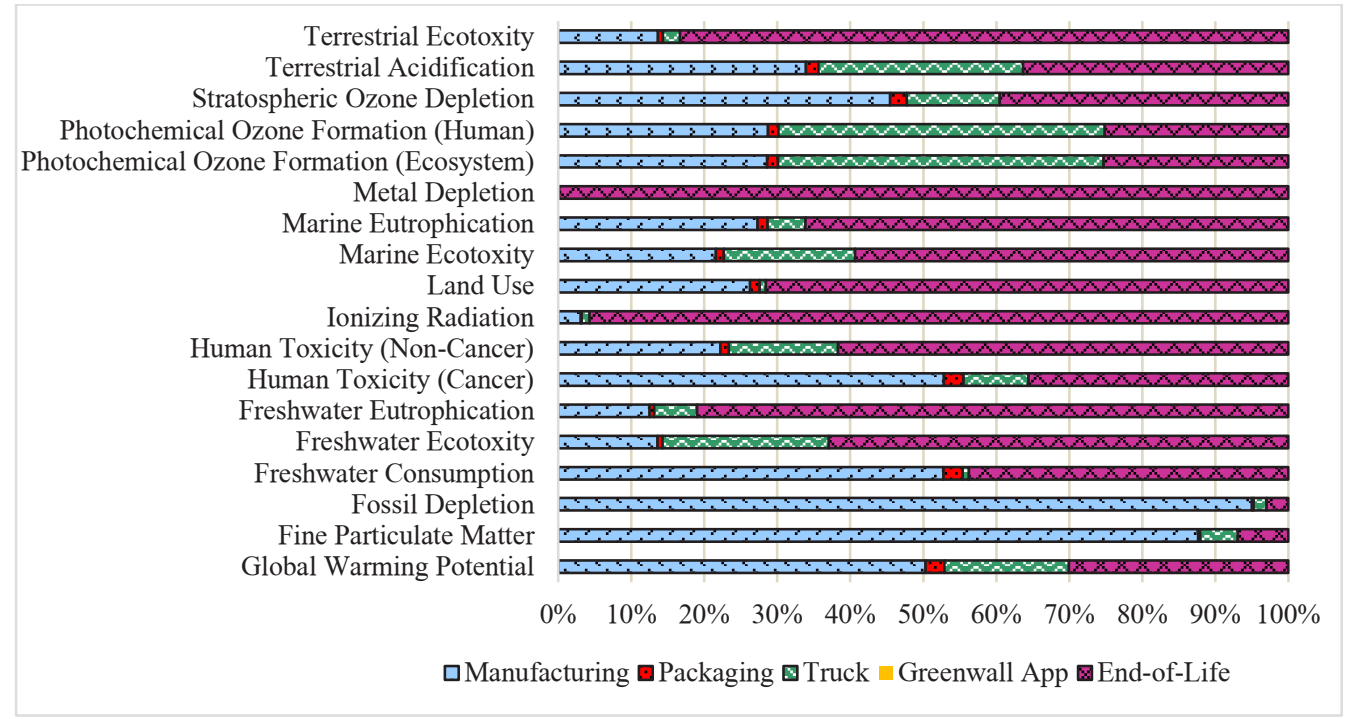

Fig. 4. Impact assessment for perlite cradle-to-grave system boundary

\subsubsection{Comparison between the environmental impacts of coir pith and perlite}

In the previous sections, the environmental impacts contributed by the coir pith and perlite were discussed based on the respective impact categories. However, to find the type of filter media that has the least environmental impact, the impact magnitude of the entire life cycle of the filter media will be compared based on significant impact categories. To begin with, based on global warming potential, the coir pith has a higher global warming potential than perlite. This is mainly due to the significant amounts of methane and carbon dioxide released through the retting process and also the composting process that releases methane and nitrous oxide [21]. These gases are main components of the GHG. For perlite, the global warming potential is significantly lower than coir pith. Perlite main contribution to the global warming potential is from the burning of natural gas to fuel furnace and the landfill [23]. However, the contribution of GHG produced from these sources does not impact the global warming potential as much as that of the coir pith. Next for fossil depletion, perlite has the higher magnitude of impact than coir pith. For perlite, the main contributor to fossil depletion is the natural gas used as the main component to fuel the furnace to a high temperature, thus requiring high quantity of natural gas [23]. However, in the case of coir pith, the contribution to the category is mainly due to the electricity consumption and the diesel used for 
transportation, which also applies to the perlite. The freshwater consumption can be seen to be higher in for coir pith than perlite. Coir pith requires water consumption for the washing of the retted coir pith to remove any dirt or sedimentation, while perlite does not have any significant usage of water [18]. In terms of terrestrial ecotoxicity, perlite has a higher impact than coir pith in this category. This is mainly due to the disposal of perlite to the landfill, whereby toxic substances get released when different components interact. For coir pith, the main contribution to this category is due to the electricity flow that contains toxic substances. Based on the Table 4, it shows for different impact categories, either coir pith or perlite has the lower environmental impact. This depends on each stages in the life cycle and the magnitude the components contribute to each impact category.

Table 4. Impact Categories for Coir Pith and Perlite system boundary.

\begin{tabular}{|l|c|c|}
\hline Impact Categories & Coir Pith & Perlite \\
\hline Global Warming Potential (kg CO 2 eq.) & 1.19568 & 0.0145799 \\
\hline Fine Particulate Matter (kg PM2.5 eq.) & 0.00003428 & 0.0000999 \\
\hline Fossil Depletion (kg oil.eq) & 0.003948 & 0.045562 \\
\hline Freshwater Consumption (m ${ }^{3}$ ) & 0.00066295 & 0.000033214 \\
\hline Freshwater Ecotoxity (kg 1,4-DB eq.) & $3.725 \times 10^{-7}$ & $9.405 \times 10^{-7}$ \\
\hline Freshwater Eutrophication (kg P eq.) & $2.351 \times 10^{-9}$ & $9.266 \times 10^{-9}$ \\
\hline Human Toxicity (Cancer) (kg 1,4-DB eq.) & $3.889 \times 10^{-6}$ & $4.049 \times 10^{-6}$ \\
\hline Human Toxicity (Non-Cancer) (kg 1,4-DB eq.) & 0.000294608 & 0.000606286 \\
\hline Ionizing Radiation (Bq. C-60 eq. to air) & $7.033 \times 10^{-7}$ & $1.175 \times 10^{-5}$ \\
\hline Land Use (Annual crop eq. yr) & 0.308071756 & 0.00015883 \\
\hline Marine Ecotoxity (kg 1,4-DB eq.) & $2.421 \times 10^{-6}$ & $4.888 \times 10^{-6}$ \\
\hline Marine Eutrophication (kg N eq.) & $8.533 \times 10^{-6}$ & $6.506 \times 10^{-8}$ \\
\hline Metal Depletion (kg Cu eq.) & $2.595 \times 10^{-6}$ & 0.000915503 \\
\hline Photochemical Ozone Formation (Ecosystem) (kg NOx eq.) & 0.000068569 & 0.000084554 \\
\hline Photochemical Ozone Formation (Human) (kg NOx eq.) & 0.000068329 & 0.000084085 \\
\hline Stratospheric Ozone Depletion (kg CFC-11 eq.) & $1.757 \times 10^{-7}$ & $2.179 \times 10^{-9}$ \\
\hline Terrestrial Acidification (kg SO eq.) & 0.00020921 & 0.0000546 \\
\hline Terrestrial Ecotoxicity (kg 1,4-DB eq.) & 0.002110001 & 0.008508135 \\
\hline
\end{tabular}

\section{Conclusion}

In conclusion, in this research was conducted evaluate and compare the effects of different filter medias for pollutant removal in greywater using greenwall technology. By conducting a literature survey by analyzing journals, peer reviewed papers and articles the capabilities of each filtering media for pollutant (COD and TSS) removal in greywater. The results from this paper found that coir pith has a higher removal efficiency for both COD and TSS at $75 \%$ and $92 \%$ respectively compared to perlite. Perlite was found to have a COD and TSS removal efficiency of $26 \%$ and $73 \%$. The reasoning for coir pith having higher removal efficiency is due the structure of the fiber that allows for a higher retention rate and less space between the pores compared to perlite. From these results, the filter medias individual capabilities in filtration is identified thus useful when a filtration media selection is required for greenwall design for greywater treatment.

Besides this, this research also focuses identifying the environmental impacts caused throughout the life cycle of the filter medias for greenwall technology using LCA. The steps to conduct this research objective consists of goal and scope definition, inventory analysis and impact assessment using GaBi software under ReCiPe model. The data obtained was interpreted and analyzed to identify the environmental impacts of each filter media. From the LCA conducted, it was found that the coir pith contributed to a higher environmental impact 
in global warming potential and freshwater consumption compared to perlite. This was mainly due to the manufacturing process that releases large amounts of GHG during retting process and the need for freshwater for cleaning and rinsing the perlite after retting process. Perlite was found to contribute to a higher environmental impact in terms of fossil depletion and terrestrial ecotoxicity compared to the results of coir pith. These results are mainly contributed by the use of natural gas needed to heat the furnace to high temperatures for perlite expansion and the disposal of perlite to the landfill during the end-of-life respectively. From conducting LCA on different filter medias, a systematic evaluation of the environmental impacts related to each material is generated. Through this research, the detailed identification of each unique process for the entire life cycle of the filter medias will be obtained. Systematic evaluations conducted enables to quantify environmental releases such as a quantifiable amount of carbon dioxide or sulfur dioxide that is released from each stage to air, water and land. Besides that, the human and ecological effects of each of these emissions or material usage can be assessed. By conducting this LCA, it can be known the extent of each impact in specific impact categories of the emissions and material usage on a quantifiable basis. The outcomes of this research will provide a clear insight in regards to the environmental aspects that is effected by these filters. The LCA will contribute knowledge for future research or selection purpose that requires in depth data regarding the usage and entire life cycles of filter medias.

From this entire research paper, an in-depth understanding of the 2 filter medias pollutant removal capabilities and magnitude of environmental impact contributed has been identified and analyzed. These results can be used as a decision making tool when designing a greenwall system for greywater treatment to find the suitable type of filtering media needed for the system.

The authors are grateful for Taylor's University for the support and facilities provided needed to complete this research paper.

\section{References}

1. K. Watkins, Hum. Dev. Rep, 77, 44 (2006).

2. E. Eriksson, M. Henze, A. Ledin, Symp. Mars, 45, 84 (2001).

3. Y. Boyjoo, V. Pareek, M. Ang, Water. Sci. Technol, 67, 1403 (2013).

4. M. Oteng-Peprah, M. Acheampong, N. deVries, Water Air Soil Pollut. 229, 255 (2018).

5. E. Noman, A. Al-Gheethi, B. Talip, R. Radin Mohamed, H. Nagao, A. Mohd Kassim, Management of Greywater in Developing Countries (Springer, Cham, 2018).

6. M. Rysulova, D. Kaposztasova, Z. Vranayova, IOP Conf. Series: Mat. Sci. Eng, 245, 1 (2017).

7. V. Prodanovic, K. Zhang, B. Hatt, D. McCarthy, A. Deletic, Build. Environ. 131, 99 (2018).

8. H. Feng, K. Hewage, J. Clean. Prod. 69, 91 (2014).

9. M. Ottelé, K. Perini, A. Fraaij, E. Haas, R. Raiteri, Energy. Build. 43, 3149, (2011).

10. G. Barrett, P. Alexander, J. Robinson, N. Bragg, Sci. Hortic. 212, 220 (2016).

11. G. Vijayakumar, R. Tamilarasan, M. Dharmendirakumar, J. Mater. Environ. Sci. 3, 157, (2012).

12. M. Finkbeiner, A. Inaba, R. Tan, K. Christiansen, H. Klüppel, Int. J. Life Cycle Assess. 11, 80 (2006).

13. L. Peano, Y. Loerincik, M. Margni, V. Rossi, Quantis Sustainability Counts Final Report, (Quantis, Lausanne, 2012).

14. Ministry of Micro, Small and Medium Enterprises, Coir Pith Wealth from Waste a Reference (Coir Board, Cochin, 2016) 
15. E. Subaida, D. K.S, Int. J. Sci. Res. 6, 287 (2016).

16. E.J. Zachariah, V. Muralidharan, Pac. Asian. J. Energy. 12, 181 (2002)

17. "Coir Beater Machine: Cleaner/Beater", Kumaran Coir, 2016. [Online]. Available: $\mathrm{http}: / /$ kumarancoir.com/coir-beater-machine.

18. Horticultural Trades Association, Towards Responsible Sourcing and Manufacture of Growing Media, (HTA, London, 2017).

19. "Coir Pith Block Making Machine", Essar Engineers, 2018. [Online]. Available: https://www.essarengineers.com/coir-pith-block-making-machine.html

20. K. Kannan, V. Selvi, D. Singh, O. Khola, R. Mohanraj, A. Murugesan, Coirpith. Comp. Broc. 1, 1 (2013).

21. A. Saer, S. Lansing, N. Davitt, R. Graves, J. Clean. Prod. 52, 234 (2013).

22. G. Goudouva, P. Loizia, V. Inglezakis, A. Zorpas, Desalination. Water. Treat. 133, 307 (2018).

23. United States Environmental Protection Agency, Compilation of Air Pollutant Emissions Factors", Office of Air Quality Planning and Standards, (EPA, North Carolina, 2007).

24. "Performance specifications of a perlite expansion plant", AMIT Industriesysteme, 2018. [Online]. Available: http://amit-online.de/en/perlite-expansion-plants/performancespecifications-of-a-perlite-expansion-plant/.

25. "Automatic Heavy Bag Big Bag BB Compound Packing Machine", Anhui Xinyuan Packing Technology Co. 2020. [Online]. Available:

https://www.sinranpack.com/automatic-heavy-bag-big-bag-bb-compound-fertilizerpacking-machine_p14.html.

26. M. Glaumann, Energy Saving through Promotion of Life Cycle Assessment in Buildings, (Enslic Building, Spain, 2020).

27. V. Prodanovic, B. Hatt, D. McCarthya, K. Zhang, A. Deletic, Ecol. Eng. 102, 625 (2017).

28. R. M. S. R. Mohamed, C. M. Chan, H. Senin, A. H. M. Kassim, J. Mater. Environ. Sci. 5, 2021 (2014).

29. M. Aravind, L. Rahna, Int. J. Eng. Adv. Tech. 8, 11 (2018).

30. A. Sharaf, Y. Liu, Chemosphere. 263, 2021 (2020).

31. E. Ganjian, M. Peyravi, A. Ghoreyshi, M. Jahanshahi, S. Khalili, A. Shokuhi Rad, Environ. Technol. 39, 2321 (2017).

32. V. Prodanovic, B. Hatt, D. McCarthy, A. Deletic, J. Environ. Manage. 261, 1 (2020).

33. A. Dabrowski, Adsorption and Its Applications in Industry and Environmental Protection, (Elsevier, Amsterdam, 1998).

34. S. Sala, L. Benini, V. Castellani, B. Vidal-Legaz, R. Pant, Environmental Footprint Update of Life Cycle Impact Assessment methods, (EC-JRC, Luxembourg, 2016). 